\title{
Fighting gentrification in the neoliberal university: displacing communities, researchers and the very possibility of radical critique
}

\author{
by Mara Ferreri and Luna Glucksberg \\ UAB (Universidat Autonoma de Barcelona); LSE, International Inequalities Institute
}

Sociological Research Online, 21 (3), 4

$<$ http://www.socresonline.org.uk/21/3/4.html>

DOI: $10.5153 /$ sro.4053

Received: 4 Apr 2016 I Accepted: 23 Jul 2016 I Published: 31 Aug 2016

\begin{abstract}
The demolition of social housing figures prominently in the most recent wave of state-led gentrification in London: fighting these processes as academics and activists presents ethical, methodological and strategic issues. We have chosen to address these issues by cautiously drawing a symbolic parallel between the conditions faced by social tenants in London, threatened with the destruction of their homes and communities, and the challenges faced by researchers who study and work within these communities, often on parttime, temporary and insecure contracts, themselves under threat of eviction from the very city they research and from academia. Navigating professional precarity and the precarity of place, we stress the need for longitudinal and ethnographic research into the effects of demolition and regeneration, whilst warning against critical urban research becoming more and more the province of tenured middle class scholars.
\end{abstract}

Keywords: Place; Precarity; Demolitions; Regeneration; Gentrification; Academia

1.1 The demolition of social housing is undoubtedly at the forefront of the most recent wave of state-led gentrification (Lees and Ferreri 2016). This brief intervention aims to respond to the journal's call by addressing two distinct but interconnected issues: firstly, where and how gentrification should be resisted, and secondly, what are the barriers encountered by committed urban scholars in universities today. We have chosen to do so by drawing a cautiously symbolic parallel between the conditions faced by tenants and residents in social housing, threatened with the destruction of their homes and communities, and the challenges faced by researchers who study and work with these communities, often on part-time, temporary and insecure contracts, themselves under threat of displacement from the very cities they research as well as from academia.

We begin by engaging critically with the role of demolition in the regeneration of social housing, specifically focussing on how it has come to be normalised as the only possible 'solution' to an ubiquitous 'housing crisis' under conditions of 'austerity' across the United Kingdom, and particularly in London. We argue that in order to observe and analyse urban regeneration, demolitions and gentrification processes ethnographically but also longitudinally, and to be able to do so in a way that is ethically useful, there is a need for researchers themselves to be 'emplaced'. Emplacement is understood not just in relation to the communities they are researching and working with, but also in their personal and academic lives: in their families and professional homes - the university departments that employ them.

1.3 Bringing together these two threads we put forward recommendations to privilege research that challenges narratives which normalise the evictions - both from the estates and academia - of its most vulnerable residents, and to focus instead on the successful challenges that have been brought to bear against demolitions, evictions and the neoliberal urban project as a whole. 


\section{Social housing demolition and gentrification: old and new narratives}

2.1 Systematically neglected and underfunded across Europe and North America, and thoroughly stigmatised by mass media, politicians and the general public (Hanley 2007), social housing has played an important role internationally as a barrier to gentrification (Ley and Dobson 2008). Its presence has maintained pockets of low-income housing that were seen to 'dapple' the map of rapidly gentrifying cities such as London (Butler and Robson 2003).

2.2 The 'regeneration' of social housing estates has been for nearly two decades presented not only as inevitable but also as morally right, as shown in the parallels between regeneration and recycling discourses explored by Glucksberg (2014). Despite prolonged struggles to fend off privatisation in the 1980s and 1990s (Watt 2009), 'regeneration' through the introduction of private ownership and private rental has been heralded as progress in social engineering, moving from allegedly homogeneous communities to fabled 'mixed communities' (Bridge et al 2012).

2.3 The planned demolition of social housing is indicative of a radical push towards wholesale disinvestment into social services across the country, with a politics of 'austerity' dominating economic strategies affecting all sectors of society, while damaging more deeply the most vulnerable of all (Montgomerie and Tepe-Belfrage 2016). Public spending by local authorities has been deeply affected, while social housing is portrayed by policymakers across the political spectrum as both an unsustainable burden to taxpayers and as a development opportunity (DCLG 2014; Adonis and Davies 2015).

2.4 In London alone, community groups have estimated that between 2005 and 2032 over 70 council estates have been or will be affected by 'regeneration' schemes, many of which require wholesale estate demolition and redevelopment as mixed-tenure, with more than $820,500 \mathrm{~m} 2$ of land changing ownership from public to private, affecting over 150,000 Londoners, between tenants, leaseholders and freeholders (Mapping London Housing Struggles 2015).

2.5 The vast majority of these estates, increasingly referred to by central government as 'brownfield sites' (DCLG 2014), are situated in valuable central locations: it is the land they sit on that becomes an attractive and disposable asset for local governments (LTF et al 2014). Estates such as the Heygate and the Aylesbury in the borough of Southwark, the Carpenters in the borough of Newham, the West Kensington and Gibbs Green, between Westminster and Kensington and Chelsea, are prime examples of this logic.

2.6 In most cases demolition is presented as the only financially 'viable option' for the private and/or third sector developers tasked by local authorities with the regeneration, often through private-public partnerships, despite evidence to the contrary being discussed both in academic and policy circles (GLA 2015). In selected cases, the building themselves are of value by virtue of their heritage listing, as is the case with Ernö Goldfinger's Balfron Tower in Tower Hamlets, first privatised, then 'decanted', and finally refurbished for private sale (see Roberts 2015).

\section{The 'housing crisis' and the demolition consensus}

3.1 Recently and more insidiously, the demolition of social housing has become central to the emergent rhetoric of the most recent 'housing crisis'. Estate demolition has been heralded as a solution to the existing shortage of housing in the capital, which is allegedly addressed by increasing density of dwelling on former estate grounds. In a mediatic sleight of hand, a compounded crisis of quantity (number of dwellings) and quality (affordability) has been repeatedly presented as a mere question of increased supply.

3.2 Modernist housing estates, traditionally built to Parker Morris standards and favouring family dwellings over one and two-bedroom apartments, are generally considered of low density, compared to notions of 'compact' high rise building that dominate the residential development scenario (Allen 2008). This of course contrasts sharply with the demolitions of high-density housing that took place in the 1990s (Glucksberg 2016) and were predicated upon the need to decrease density, leading to thousands of families being displaced from their homes.

3.3 Politically, thus, the very existence of social housing estates is represented as a barrier to providing solutions to the housing crisis; in the scramble for central land on which to build, council housing becomes disposable. Despite the 2016 mayoral electoral campaign being dominated by the housing issue (BBC News 2016), old tropes about 'sink estates' and the dogma of 'regeneration' by demolition are still prevalent, as was 
recently exemplified by former Labour cabinet member Lord Andrew Adonis's report for the Institute of Public Policy Research (IPPR), which proposed the transformation through redevelopment of existing council estates into 'city villages' (Adonis and Davies 2015; Cfr. Bowie 2015). In a political and policy landscape marked by such consensual views on the disposability of social housing we argue that there is an even stronger need for committed research into the relationship between gentrification and social housing demolition, and into the personal and collective consequences of the displacement of its residents.

3.4 As a process of managed decay the direct and indirect displacement of low income populations constitutes a violent unmaking, symbolic and physical, of place as well as of emplacement itself, of the relations of trust and mutual respect that co-constituted social housing residents' sense of belonging and of a having the 'right to stay put'. It is in this context that a committed and emplaced approach to gentrification is needed, to understand and scrutinise its focus and its politics of representation.

3.5 While many critical urban studies of gentrification insist on denouncing the current state of affairs by presenting social tenants and residents as victims, we argue that insisting on dispossession can be a doubleedge sword, as the association of certain populations with trauma and negative events contributes to their depiction as in a perpetual state of emergency, further adding to their stigmatisation as problematic urban 'other'. How, then, to articulate an analysis of social housing demolition that is politically and ethically situated, attuned to personal experiences and forms of resistance without reproducing disempowering narratives of victimhood?

\section{Methodological issues}

4.1 Answering this question requires more than a disciplinary overview: it requires developing a research compass that enables positioning in relation to ethical, methodological and productive issues, and attentiveness to the multiple conditions and forms of anti-displacement resistance and political organising (see Tracy 2014). Displacement is articulated not just temporally and spatially, as an enforced movement of people, but also across multiple modes of relations and through a range of places.

4.2 The challenge for researchers is to understand how dynamics that operate, simultaneously, at national, international and local scales, are visible and relevant for drastic changes at the perceptible level: individuals, households, estates. This requires understanding the role of local governance and planning bodies, of transnational capital (Glucksberg 2016), of the complex, long histories of a place and of political alliances.

4.3 An ethnographic approach to the relationship between gentrification and social housing demolition is necessary to bring out the complex and interconnected processes through which the devaluation and displacement of communities and people, especially low income tenants and leaseholders, happen, as well as to analyse and understand the ways in which people's lives are affected by them over the long term (McKenzie 2015; Paton 2014).

4.4 More broadly, such an approach can enable a greater degree of methodological openness and the possibility of 'slow scholarship' in the 'research design, community engagement, and pursuit of personally and politically meaningful work' (Mountz et al 2015, p. 1244). 'Slow' and emplaced research can offer the grounds for greater attentiveness to the research process and to the complex power relations at play in situations of urban conflict, particularly when entire communities are made invisible or stigmatised in public representations

4.5 From a commitment to concrete situations, committed urban research should therefore move towards an approach that strategically combines individual and collective narratives with a detailed and multidisciplinary systemic critique capable not only of identifying significant events and actors, but also concrete instances where rigorous critical scholarship can make a difference. As committed researchers on gentrification the normative question of where and how should gentrification be resisted is inevitable and also inexorably linked to the open questions of what kinds of knowledge should be produced. How should this production take place? How can it foster and accompany processes of resistance? It can do so for instance through producing supporting evidence as part of Public Inquiries (Lees and Ferreri 2016) or through the production and distribution of non-academic outputs, such as the booklet Staying Put: An anti-gentrification handbook for council estates in London(LTF et al 2014).[1]

\section{The question of impact}

5.1 The slow work of researching, contributing to processes of resistance and disseminating findings through non-conventional channels, could be highly valued by academia, bringing us to the political and 
conceptual knot of engaging in 'impact' research, which in the United Kingdom recently became a component of the audit culture associated with the Research Excellence Framework (REF). Considerable debate has emerged in critical and radical geographical scholarship, with the impact agenda being cautiously welcomed by scholars engaged for a long time in participatory research (Pain et al 2011) while critiqued by others as a further neoliberal instrumentalisation of autonomous knowledge production (Slater 2012; see also the response by Pain et al 2012).

The metrics associated with the impact agenda have been argued to have a disciplining effect that further marginalises experiences of collaboration and dissemination that are not quantifiable (Williams 2012). In this context, arguments have been made for shifting from 'a linear notion of impact as striking a blow' (Pain 2014: 21), towards feminist knowledge production as relational, non-hierarchical and taking place through 'a more diverse and porous series of smaller transformative actions that arise through learning among all of those involved' (Pain 2014: 21; see also Pain et al 2016).

5.3 In the specific context of gentrification research, the task at hand is to share and sustain different value practices in which the process of collaboratively shaping research agendas, of openness to active participation and non-hierarchical learning are considered intrinsic to committed research on gentrification; this kind of work requires a shift from the temporalities of research to those of public engagement and a degree of commitment to place, both of which are hard to sustain in neoliberal academia.

\section{Displacing researchers?}

6.1 The possibility of committed ethnographic and longitudinal research, aiming to move beyond ideas of impact as striking a blow, are undermined by the precarious living and labour conditions experienced by lecturers and researchers in universities in the UK. Based on statistical data provided by HESA, the University and College Union (UCU) has recently estimated that there are more than 100,000 university teachers in the UK who do not have a secure contract; this amounts to more than half of the total, and a large number of this casualised workforce are on hourly paid and zero-hour contracts (2016), mirroring conditions for research staff. Moreover, the flexibility of work and place demanded by a 'professional commitment' to academic institutions and scholarship is often translated in constant household uprooting or extensive and prolonged commuting, which become physical if not social and cultural barriers to developing the kinds of sustained relations that enable collaborative learning and building trust.

6.2 Whilst we would not dream of comparing the housing difficulties and struggles faced by precarious academics with those of the estate's residents that are usually the subjects of long terms research into the impacts of gentrification, it is nonetheless significant that the conditions of existence for young and not so young ECRs (Early Career Researchers) are being eroded at the same time as the demolitions of the estates they do their research in gather momentum.

6.3 In London a room in a shared house in the ever-growing Private Rented Sector (DCLG 2015) - virtually the only tenure available to precarious academics - often requires $50 \%$ of monthly income in rent when based on a PhD scholarship (average $£ 14,000$ p.a., ESRC). A similar proportion of an ECR salary is needed to rent an average one-bedroom flat. The issue with PRS housing is not simply financial: the effect of one-year tenancies, the norm in PRS rental agreements (Kemp 2011; see also, LSE-London 2015), is a growing insecurity of tenure, with important social and cultural implications as new generations increasingly struggle to become accustomed to heightened personal precarity (Bone 2014).

6.4 The problem here is, crucially, the increasing impossibility for researchers to become 'emplaced' and to engage in long-term, sustained relationship with communities and places when they are themselves subjected to year-by-year displacement or threat of displacement.

6.5 As engaged and emplaced research into gentrification becomes unaffordable to postgraduate students and ECR, it risks to become a topic available only to established academics, who in turn may struggle to find 'slow time' for place-specific engagement while juggling the demands for academic outputs and professional development (Mountz et al 2015). Critical social research and academia more broadly in global cities may become more and more the province of affluent and middle class scholars, of those independently wealthy or who have partners with substantial salaries to support them through academic precarity and precarity of place.

\section{Concluding reflections}


7.1 Once social housing estates are physically demolished, replaced by higher value housing for higher income residents, reclaiming that land for poorer and more diverse inhabitants will become incredibly difficult, if not impossible. Faced with such an urban sea change, it is our contention that committed research has a role to play to resist it. At the same time, both cities and academia are becoming more exclusive, and the critical voices of $\mathrm{PhD}$ students and ECRs are themselves at risk of displacement, in a vicious loop that will ultimately undermine not just critical voices, but the possibility of radical critique itself.

"Where and how should gentrification be resisted?" One answer has to be outside of academia, through politically engaged work with communities and residents that organise in response to these processes. In this context, committed researchers could be looking for and learning lessons from the, admittedly few and far between, examples of gentrification resistance that have successfully managed to challenge the prospects of demolition and displacement of local communities. Even when struggles were not ultimately successful, and only small or partial victories were achieved, all the same it is important to amplify them and make them resonate. Strategically, we need to learn what works, in order to replicate it: even within an understanding that personal and local issues and circumstances matter we must learn to share good practice that brings good, effective results, whether that may be acting strategically towards decision-makers at different levels, finding alliances with unlikely groups or using new media and legal tactics. In the search for allies, it is clear that resistance has to occur within academia too, through valuing committed scholarship and enabling more secure conditions for those working on urban gentrification and for emplaced research in general.

In challenging the powerless and helpless narratives that normalize defeat, we need to remind ourselves that the wholesale destruction of social housing is not inevitable. In the UK, a high proportion of social housing was built in the wake of WWII, in a country that was on its knees in every possible way, and yet, thanks to pressure from below, historical steps were taken towards housing its citizens with dignity. We are now witnessing a complete reversal of that political consensus. The question of the future of social housing today would therefore benefit from an approach in which social scientists, working alongside activists and residents, can inform and contextualise the struggles that we study or are part of, give them resonance beyond their local specificities and understand and disseminate powerful counter-examples. In order to do so our task will have to be, simultaneously, that of denouncing the political and ideological nature of regeneration policies, of actively participating in struggles and of promoting the value of long-term, emplaced and engaged urban research. It is only in this way that we can challenge gentrification processes on every front, as residents, researchers and most of all communities of resistance.

\section{Notes}

Distributed in council estates' community halls, at workshops, public open talks and housing network meetings, as well as available for online download.

\section{References}

ADONIS, A and Davies, B (Eds) (2015) City Villages: more homes, better communities London: Institute for Public Policy Research.

ALLEN, C. 2008 Housing Market Renewal and Social Class, Oxon: Routledge.

BBC NEWS (2016) London mayoral election: Housing top concern, poll suggests, 1st April 2016: http://www.bbc.co.uk/news/uk-england-london-35936907.

BONE, J. (2014) Neoliberal Nomads: Housing Insecurity and the Revival of Private Renting in the UK. Sociological Research Online, 19(4), 1 http://www.socresonline.org.uk/19/4/1.html.

BOWIE, D (2015) The wrong solution to London's housing crisis. Redbrick blog 31 March 2015.

BRIDGE, G, Butler, T, and Lees, L (2012) Mixed communities: Gentrification by stealth? Oxford: Policy Press. 
BUTLER, T with G. Robson (2003) London Calling: The Middle Classes and the Remaking of Inner London Oxford: Berg.

DCLG (2014) 'Government initiatives to help build more new homes on brownfield land' press release, 13 June 2014, < https://www.gov.uk/government/news/government-initiatives-to-help-build-more-new-homes-onbrownfield-land>

DCLG (2015). English Housing Survey: Trends in tenure, London and England, 2003-04 to 2013-14. London: Department for Communities and Local Government.

GLUCKSBERG, L (2014) "We was regenerated out": regeneration, recycling and de-valuing communities', Valuation Studies 2(2), p. 97-118. [doi:10.3384/vs.2001-5992.142297]

GLUCKSBERG, L (2016) The Five Estates: An Ethnographic approach to Regeneration and Displacement in Inner-city London. In P. Watt and P. Smets (Eds.) Public/Social Rental Housing and Urban Renewal: New Inequalities and Insecurities? Bingley: Emerald.

GLUCKSBERG, L (2016) A view from the top: unpacking capital flows and foreign investment in the Alpha Territories of London, City: Special Issue on the Global Housing Crisiseds. Paul Watt and Anna Minton, p. 248-265. [doi:10.1080/13604813.2016.1143686]

GREATER LONDON AUTHORITY (GLA) (2015) Knock it Down or Do it Up? The challenge of estate regeneration. London: London Assembly Housing Committee.

HANLEY, L (2007) Estates: An Intimate History. London: Granta.

KEMP, P A (2011) Low-income tenants in the private rental housing market,Housing Studies 26, p. 1019-1034. [doi:10.1080/02673037.2011.615155]

LEES, L and Ferreri, M (2016) Resisting gentrification on its final frontiers: Learning from the Heygate Estate in London (1974-2013), Cities.

LEY, D. and Dobson, C. (2008) Are There Limits to Gentrification? The Contexts of Impeded Gentrification in Vancouver, Urban Studies, 45 (12), p. 2471-2498. [doi:10.1177/0042098008097103]

LONDON TENANTS FEDERATION, Lees, L, Just Space and SNAG (2014) Staying Put: an Anti-Gentrification Handbook for Council Estates in London:http://southwarknotes.wordpress.com/2014/06/13/staying-putan-anti-gentrification-handbook-for-council-estates-in-london/.

LSE LONDON (2015) PRS Profiles: Learning from tenants' experiences to improve private renting in London report. London: LSE London.

MCKENZIE, L (2015) Getting By: Estates, Class and Culture in Austerity Britain Bristol: Policy Press.

MAPPING LONDON HOUSING STRUGGLES (2015) London's Housing Struggles 2005-2032: https://mappinglondonshousingstruggles.files.wordpress.com/2013/03/london-housing-strugglesmap_dec-2014_low-res.pdf.

MOUNTZ, A, Bonds, A, Mansfield, B, Loyd, J, Hyndman, J, Walton-Roberts, M, Basu, R, Whitson, R, Hawkins, R, Hamilton, T and Curran, W, (2015) For slow scholarship: A feminist politics of resistance through collective action in the neoliberal university. ACME: An International E-Journal for Critical Geographies, 14(4), p. 1235-1259.

PAIN, R, Kesby, M, and Askins, K (2011) Geographies of impact: power, participation and potential.Area, 43(2), p. 183-188. [doi:10.1111/j.1475-4762.2010.00978.x]

PAIN, R, Kesby, M, and Askins, K (2012) The politics of social justice in neoliberal times: A reply to Slater Area, 44(1), p. 120-123. [doi:10.1111/j.1475-4762.2011.01073.x]

PAIN, R (2014). Impact: Striking a blow or walking together?, ACME: An International E-Journal for Critical Geographies, 13(1), p. 19-23.

PAIN, R, Askins, K, Banks, S, Cook, T, Crawford, G, Crookes, L, Darby, S, Heslop, J, Holden, A, Houston, M and Jeffes, J (2016) Mapping Alternative Impact: Alternative approaches to impact from co-produced 
research. Durham: Centre for Social Justice.

PATON, K (2014) Gentrification: A Working-Class Perspective. Ashgate.

ROBERTS, D (2015) Balfron Tower: a building archive: http://www.balfrontower.org/.

SLATER, T (2012) Impacted geographers: A response to Pain, Kesby and Askins Area, 44(1), p. 117-119. [doi:10.1111/j.1475-4762.2011.01067.x]

TRACY, J (2014) Dispatches Against Displacement: Field Notes from San Francisco's Housing Wars AK Press.

WATT, P (2009) Housing stock transfers, regeneration and state-led gentrification in London,Urban Policy and Research 27(3), p. 229-242. [doi:10.1080/08111140903154147]

WILLIAMS, G. (2012) The disciplining effects of impact evaluation practices: negotiating the pressures of impact within an ESRC-DFID project. Transactions of the Institute of British Geographers, 37(4), p. 489-495. 